\title{
Avaliação de impactos socioambientais na Gruta da Lapinha, Lagoa Santa/MG e seu entorno pela atividade turística
}

\author{
Assessment of the socioenvironmental impact of tourist activity in the Lapinha Grotto, Lagoa \\ Santa, Minas Gerais and the surrounding area \\ Evaluación de impactos sociambientales en la Gruta de la Lapinha - Laguna Santa / MG - y \\ su entorno por la actividad turística
}

\author{
Fernanda Vieira Xavier ${ }^{1}$ \\ Rafael Deslandes Ribas ${ }^{2}$ \\ Adalto Moreira Braz
}

Recebido em 04/2017. Aprovado em 07/2017.

\begin{abstract}
RESUMO: O presente trabalho teve como objetivo principal avaliar qualitativamente as interferências decorrentes da atividade turística que ocorrem na gruta da Lapinha em Minas Gerais, caracterizando seus aspectos socioambientais e identificando seus impactos ocorridos em função da visitação turística. Foi realizado um levantamento bibliográfico e pesquisas em campo para identificar um panorama da atual situação da gruta, além da realização da matriz de correlação através do método Check List a fim de avaliar os principais impactos. Os resultados mostraram diferentes percepções da comunidade sobre a preservação do patrimônio além de apontar os principais problemas decorrentes da degradação ambiental da área. Como considerações finais, foram realizadas recomendações para melhoria da preservação e da relação da comunidade com a Unidade de Conservação.
\end{abstract}

Palavras-chave: Impactos Socioambientais; Matriz de Correlação; Gruta da Lapinha.

ABSTRACT: By characterizing the socioenvironmental aspects and identifying its consequences, the main focus of this work was to qualitatively evaluate the interference caused by the activities relating tourism that occur in the Lapinha Grotto in Minas Gerais. A bibliographic survey and field research were carried out to identify the extent of the grotto's current status, along with a correlation matrix using the Check List method in order to evaluate the main impact. Besides pointing out the main problems due to environmental degradation of the area, the results show different perceptions by the community on the preservation of the patrimony. Finally, recommendations were made on how to improve preservation and the community's relationship with the Conservation Unit.

Key words: Socioenvironmental Impact; Correlation Matrix; Lapinha Grotto.

RESUMEN: El presente trabajo tuvo como objetivo principal evaluar cualitativamente las interferencias consecuentes de la actividad turística que ocurre en la gruta de la Lapinha en Minas Gerais, caracterizando sus aspectos socioambientales e identificando los impactos dados en función de la visita turística. Fue realizado un levantamiento bibliográfico y de trabajos de campo para identificar un panorama de la actual situación de la gruta, además de elaborarse la matriz de correlación a través del método Check List con el fin de evaluar los principales impactos. Los resultados mostraron diferentes percepciones de la comunidad sobre la preservación del patrimonio, como también apuntaron los principales problemas consecuentes de la degradación ambiental del área. Como consideraciones finales, se hicieron recomendaciones para la mejoría de la preservación y de la relación de la comunidad con la Unidad de Conservación.

Palabras-clave: Impactos Socioambientales; Matriz de Correlación; Gruta de la Lapinha.

Geografia (Londrina) v. 26. n. 1. p. $19-33$, jan/jun, 2017.

ISSN 2447-1747 


\section{INTRODUÇÃO}

Inúmeros registros arqueológicos pré-históricos que indicam ocupação humana principalmente em ambientes cársticos - estão associados às cavernas. São sítios com ossadas, artefatos indígenas esculpidos em pedras, ossos, cerâmicas, vestígios de fogueiras, pinturas e inscrições rupestres.

Ao longo do tempo, estes ambientes sofreram transformações em função dos interesses diversos no seu uso, sobretudo associados à explorações de recursos minerais (PROUS, 1998). Além da mineração, outra atividade intensa ocorrente neste tipo de ambiente é o turismo, conhecido como espeleoturismo. As intervenções que ocorrem nas cavernas, extremamente frágeis do ponto de vista geológico e biológico, geram impactos muitas vezes irreversíveis e medidas que direcionem para ações de conservação destes patrimônios se tornam necessárias.

A visitação em cavernas é motivada para contemplação e destinada a expedições científicas, para estudos de maior complexidade. Tais estudos são realizados por uma ciência chamada espeleologia. Cabe à espeleologia estudar o meio subterrâneo, abrangendo os aspectos bióticos, abióticos, históricos e as suas relações com a sociedade nas mais diversas formas.

Com as visitações e as atividades que afetam direta, e indiretamente as cavernas, os seres que ali vivem, sofrem perturbações que podem levar à extinção de algumas espécies da biodiversidade, sobretudo endêmicas. Tais interferências geram a desestruturação no ambiente interno ou externo de uma caverna, comprometendo todo o estado de conservação da mesma e interferindo no modo de vida dos animais troglóbios - únicos animais que habitam uma caverna protegidos por lei Federal. Os animais troglóbios possuem características próprias, como a ausência de olhos na maioria das espécies, falta de pigmentação, entre outras. Podem ser peixes, aranhas e crustáceos.

O presente trabalho teve como objetivo principal avaliar qualitativamente as interferências decorrentes da atividade turística que ocorrem na gruta da Lapinha e sobretudo em seu interior de formação cárstica.

Os objetivos específicos foram a caracterização dos aspectos socioambientais da região onde se localiza a gruta e a identificação dos impactos ambientais positivos e negativos ocorridos na área de visitação em função do ecoturismo para assim refletir sobre sua viabilidade turística.

É importante ressaltar que a escolha da gruta da Lapinha como objeto de estudo, se dá devido ao importante potencial socioeconômico que a gruta representa para a região, pois com a chegada de turista há geração de empregos diretos e indiretos para a comunidade local, desde que previamente estudadas as formas adequadas a subsidiar um 
plano de manejo que permita a manutenção da visitação simultaneamente à sua conservação.

\section{CARACTERIZAÇÃO DA ÁREA DE ESTUDO}

A gruta da Lapinha descoberta por Peter Lund em 1835, encontra-se em um maciço de formação geológica Pré-Cambriana (600 milhões de anos) pertencente ao município de Lagoa Santa distante aproximadamente 55 quilômetros de Belo Horizonte, Minas Gerais.

É um importante exemplar brasileiro de ambiente cárstico desenvolvido em rochas sedimentares, sendo considerado um dos mais importantes do estado, do ponto de vista turístico, já que se localiza no Parque Estadual do Sumidouro, dentro de uma APA - Área de Preservação Ambiental chamada "APA Carste de Lagoa Santa" (Figura 1).

Figura 1: Área de Proteção Ambiental - APA Carste Lagoa Santa, MG.

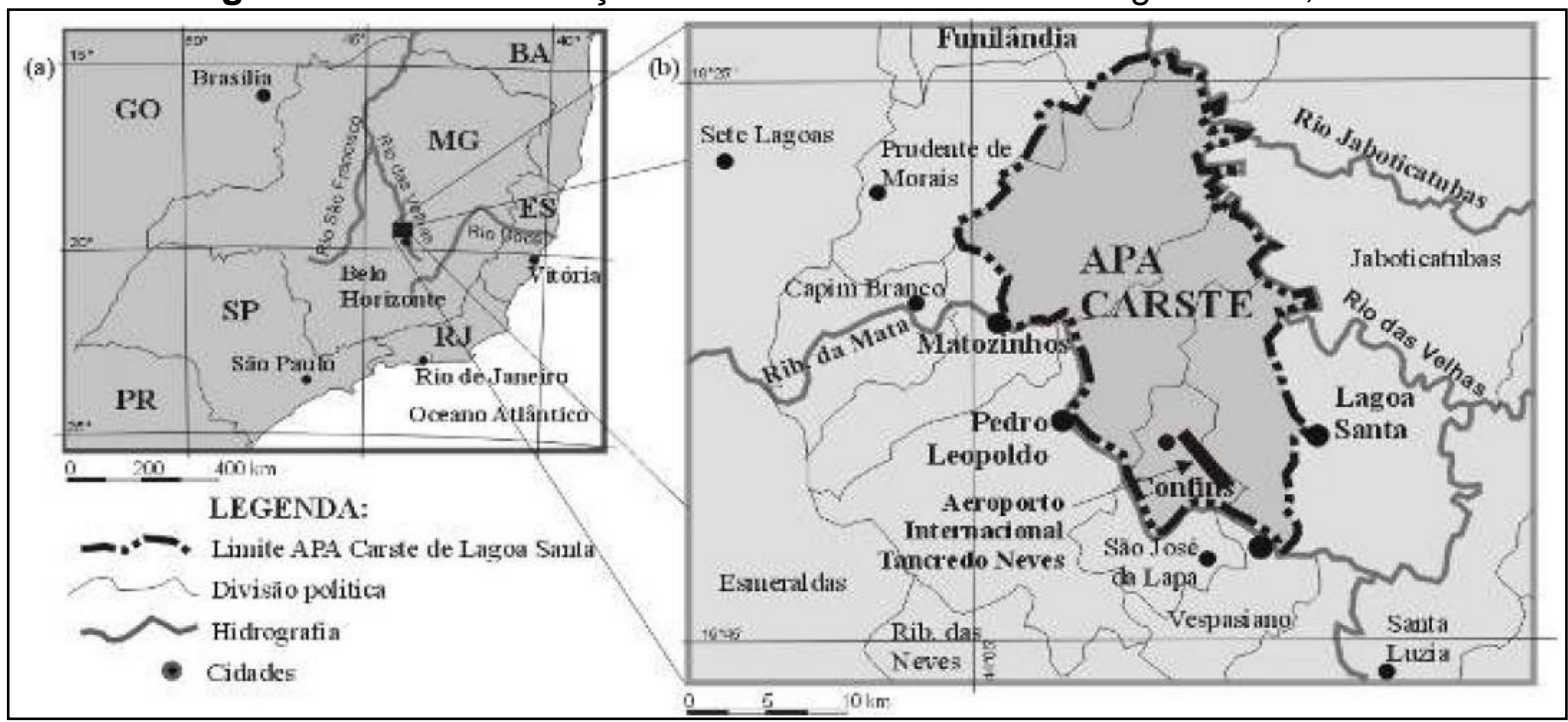

A APA Carste de Lagoa Santa foi criada com o objetivo de garantir uma relação harmônica entre as intervenções antrópicas e a preservação do patrimônio cárstico regional. As APAs correspondem a unidades de conservação em que não há uma intervenção direta do Poder Público nas porções territoriais por elas compreendidas, nem qualquer tipo de limitação direta (desapropriação) no direito de propriedade, assegurado constitucionalmente (MENDONÇA, 1998).

Conforme cita Berbert-Born (2008), o relevo da área de estudo é estruturado por rochas carbonáticas, onde a rede de drenagem é encaixada nos diversos tipos de feições geradas pelas dissolução do calcário, em ambiente configurado por dolinamentos e uvalas e Além disso, abriga um grande número de sítios arqueológicos que desperta o interesse de pesquisas neste ramo há mais de 200 anos. 
O uso e ocupação do solo no entorno da área de estudo é variado. Boa parte é preservada em função da existência do Parque do Sumidouro, porém, é possível identificar área de mineração, residências, clubes de recreação, algumas culturas, pastagem, o que implica em área desmatada, e solo exposto. A região de estudo sofreu um processo de crescimento acelerado e a população que vive ao redor do Parque tem como base econômica a agropecuária e a mineração, atividades que ficaram prejudicadas e por essa razão a legitimidade do Parque frente às comunidades vizinhas seguiu prejudicada. $A$ forma de criação de Parques no Brasil não é inclusiva, o que prejudica o desenvolvimento sustentável da região onde os mesmos se inserem (DIEGUES, 2004).

\section{METODOLOGIA}

A pesquisa foi realizada baseada em diálogos informais com a comunidade da região, levantamento bibliográfico, visitas de campo e elaboração de matriz de correlação baseada no método "check list" para avaliação dos impactos encontrados e são descritos a seguir.

\section{Visitas de campo}

As coletas de dados foram realizadas com visitas em campo para observação do entorno da gruta da Lapinha e sua condição ambiental. Foi realizado o acompanhamento a um grupo de aproximadamente 20 visitantes durante sua permanência na gruta onde foram observadas suas reações e percepções sobre o ambiente durante a caminhada.

Foi realizada também uma visita guiada com apenas um condutor a fim de atestar o nível de responsabilidade ambiental dos instrutores funcionários da gruta.

Além das atividades realizadas nas dependências da gruta da Lapinha, foi realizado um diálogo junto à comunidade local para a obtenção de dados sobre o aproveitamento do espaço e sua visitação.

\section{Check List e Matriz de Correlação}

A Avaliação de Impacto Ambiental é um instrumento de política ambiental formado por um conjunto de procedimentos capazes de assegurar, desde o início do processo, que seja feita uma análise sistemática dos impactos ambientais de uma dada ação proposta e de suas alternativas. Esta análise implica nas atividades de identificação, medição e valoração dos prováveis impactos, através de métodos e técnicas objetivas, de modo a garantir resultados consistentes.

Para a aplicação deste método foi necessária a coleta e identificação de dados que posteriormente foram listados levando em conta os principais agentes impactantes 
relacionados através do método de Avaliação de Impacto Ambiental denominado Check List - possibilitando a realização de um diagnóstico ambiental correlacionado ao turismo praticado.

De acordo com Sanchéz (2008), algumas listas catalogam impactos mais comuns associados a certos tipos de empreendimentos e outras indicam os elementos, ou fatores ambientais potencialmente afetados por determinados tipos de uso do solo.

Nesta etapa foram listados e analisados os dados como sendo negativos ou positivos como:

Quadro 1: Variáveis analisadas no Check List

\begin{tabular}{|c|c|c|}
\hline 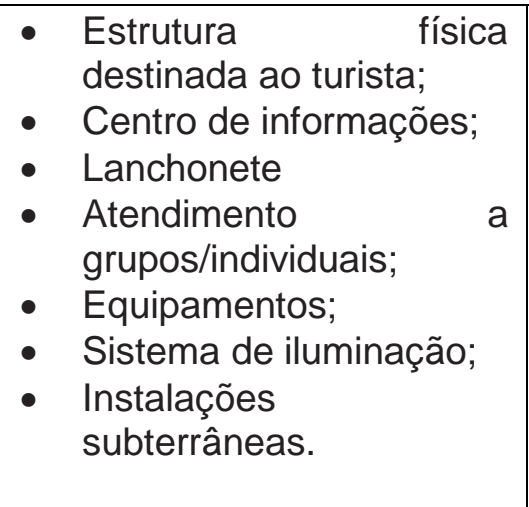 & $\begin{array}{l}\text { - Comprometimento de cursos } \\
\text { de água; } \\
\text { - Disposição inadequada dos } \\
\text { rejeitos; } \\
\text { - Comprometimento da fauna } \\
\text { e flora; } \\
\text { - Preservação de elementos } \\
\text { cavernícolas; } \\
\text { - Impactos sonoros e visuais; } \\
\text { - Nível de degradação do } \\
\text { entorno. }\end{array}$ & 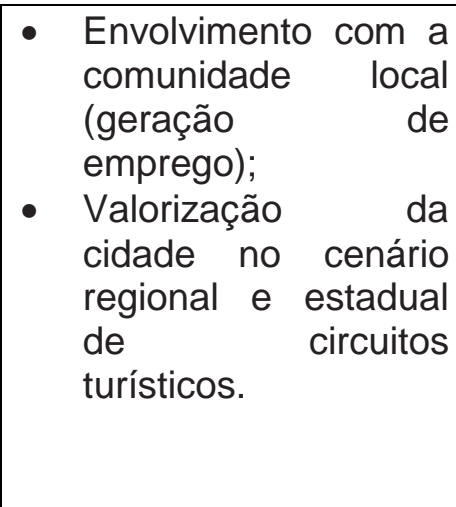 \\
\hline
\end{tabular}

O método da matriz de correlação utilizado neste trabalho segue o modelo utilizado por Sanchéz (2008). Em uma das listas são identificadas as principais atividades ou ações que compõem a área de estudo e na outra são apresentados os principais componentes ou elementos do sistema ambiental, ou ainda processos ambientais. O objetivo é identificar as interações entre sociedade e natureza.

Para a Matriz de Correlação, foram identificados os impactos potenciais e separados entre Impactos Gerais, Impactos Locais e Impactos Positivos. A matriz conta com os seguintes itens:

\section{Ações geradoras de impactos;}

2. Peso: caracteriza a importância/severidade das consequências que podem impactar o meio ambiente e/ou a população. O peso, ou importância ou ainda severidade são divididos em:

- Fraca: intensidade grau 1

- Média: intensidade grau 2

- Forte: intensidade grau 3

3. Escala: Caracteriza a extensão do impacto. É dividida em:

- Pontual: grau 1 (impacto local, ou pontual) 
- Local: grau 2 (impacto no entorno da gruta)

- Regional: grau 3 (impacto na região)

4. Valor: calcula a significância do impacto através da seguinte formula de ponderação:

\section{VALOR = PESO (SEVERIDADE) + ESCALA}

5. Classificação: através do resultado da formula VALOR, classifica-se os impactos associados aos aspectos pelos seguintes critérios:

- Impacto fraco: 1 a 2 pontos

- Impacto moderado: 3 a 4 pontos

- Impacto Forte: 5 pontos

Para verificar se a APA está realmente promovendo o desenvolvimento sustentável, foi necessário saber qual o envolvimento da população local com a Unidade de Conservação e quais são os principais problemas ambientais enfrentados por essas pessoas, através de diálogos com a comunidade.

\section{RESULTADOS E DISCUSSÕES}

\section{Matriz de correlação e Percepção geral}

A matriz foi dividida em Impactos Gerais, Impactos Locais e Impactos Positivos (Quadro 2). Observa-se que os impactos relacionados ao comprometimento da fauna, dos cursos d'água e do solo são preocupantes e já merecem medidas de recuperação/preservação. A grande parte dos impactos foi da classe "moderada", que apesar de não serem alarmantes, merecem atenção para que não se tornem da classe "forte".

Os impactos classificados como "fraco", são referentes aos impactos pontuais locais, dentro da gruta, que afetam o seu interior, e que de certa forma, prejudicam o patrimônio e a fauna específica. Da mesma forma que os impactos negativos, a magnitude da classe "forte", cabe também para os impactos positivos, a despeito de geração de emprego para os moradores locais, e para a valorização da estrutura turística da cidade no cenário regional e estadual.

Nas percepções sobre as visitas, inicialmente observou-se a iluminação do local de uma forma geral, sendo escuro e com passagens apertadas.

$\mathrm{Na}$ visita individual com um dos guias, pôde-se perceber que os colaboradores que trabalham na gruta da Lapinha possuem a consciência da importância da preservação deste ambiente. 
Quadro 2: Matriz de correlação

\begin{tabular}{|c|c|c|c|c|}
\hline \multirow{2}{*}{$\begin{array}{l}\text { Identificação dos Impactos } \\
\text { IMPACTOS GERAIS }\end{array}$} & \multicolumn{4}{|c|}{ Avaliação } \\
\hline & 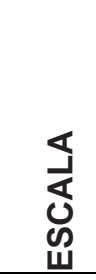 & 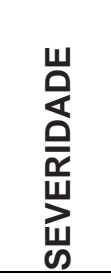 & $\frac{\text { ru }}{\frac{1}{4}}$ & 选 \\
\hline 1.Impacto visual & 2 & 2 & 4 & moderado \\
\hline 2.Supressão de vegetação & 3 & 1 & 4 & moderado \\
\hline $\begin{array}{l}\text { 3.Comprometimento de cursos } \\
\text { d'água }\end{array}$ & 3 & 2 & 5 & forte \\
\hline 4.Poluição do solo & 3 & 2 & 5 & forte \\
\hline $\begin{array}{l}\text { 5.Nível de degradação do } \\
\text { entorno }\end{array}$ & 2 & 2 & 4 & moderado \\
\hline 6.Poluição sonora & 1 & 1 & 2 & fraco \\
\hline 7.Comprometimento da fauna & 3 & 2 & 5 & forte \\
\hline $\begin{array}{l}\text { IMPACTOS ESPECÍFICOS } \\
\text { DENTRO DA GRUTA }\end{array}$ & 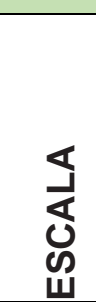 & 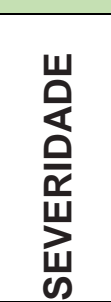 & 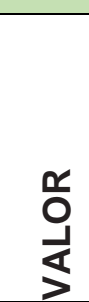 & 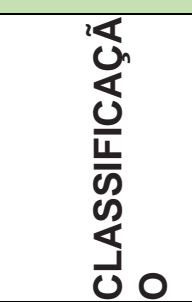 \\
\hline 1.Instalações subterrâneas & 1 & 2 & 3 & moderado \\
\hline $\begin{array}{l}\text { 2.Construção de estruturas } \\
\text { turísticas }\end{array}$ & 1 & 3 & 4 & moderado \\
\hline 3.Materiais utilizados & 1 & 2 & 3 & moderado \\
\hline 4.degradação da gruta & 1 & 2 & 3 & moderado \\
\hline $\begin{array}{l}\text { 5.Sistema de iluminação no } \\
\text { interior }\end{array}$ & 1 & 1 & 2 & fraco \\
\hline 6.Instalações no exterior & 2 & 1 & 3 & moderado \\
\hline IMPACTOS POSITIVOS & 通 & 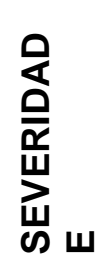 & 哭 & 芯 \\
\hline 1.Geração de emprego & 3 & 2 & 5 & forte \\
\hline $\begin{array}{l}\text { 2.Valorização do cenário } \\
\text { turístico da cidade }\end{array}$ & 3 & 2 & 5 & forte \\
\hline
\end{tabular}

Fonte: Os autores. 
Avaliação de impactos socioambientais na Gruta da Lapinha, Lagoa Santa/MG e seu entorno pela...

A estrutura para recepção de visitante é boa. A gruta da Lapinha possui um amplo estacionamento em frente à entrada do Centro de Visitantes que comporta carros, vans e ônibus, além de rampa que facilita a locomoção de pessoas portadoras de necessidades.

$\mathrm{Na}$ entrada o turista recebe as primeiras informações, e paga a taxa de $R \$ 15,00$ por pessoa (crianças e idosos são isentos). Existem jogos educativos onde os turistas conhecem um pouco mais sobre as cavernas e seus habitantes. Na visita ao Museu de Peter Lund, onde os instrutores contextualizam o turista sobre o histórico da gruta, é possível observar antigas obras e desenhos, conhecer um pouco mais sobre o Parque do Sumidouro, e até mesmo visitar uma exposição de fósseis encontrados por Peter Lund.

Apesar da existência do museu e de guias preparados que conduzem os turistas durante todo o passeio, a gruta não possui um centro de atendimento onde os visitantes possam encontrar literatura sobre a região e temas relacionados e maiores informações sobre os atrativos do Parque. São oferecidos folhetos de divulgação com informações bastante limitadas.

A gruta possui uma lanchonete que tem preferência em trabalhar com produtos locais, mas a Vigilância Sanitária proibiu o comércio de produtos caseiros, típicos da região. Hoje a lanchonete oferece aos turistas os mesmos produtos encontrados nos supermercados das cidades, o que vai contra a uma das propostas da sustentabilidade que é a de gerar renda direta e indiretamente para a comunidade. $O$ local possui ainda banheiros masculinos, femininos e adaptados para portadores de necessidades especiais.

A administração da gruta disponibiliza espaço e mão de obra suficiente e qualificada para atender a demanda de turistas individuais ou em grupos, formados em sua maioria por estudantes e espeleólogos que utilizam do espaço para estudos e treinamentos.

Para realizar a visita ao interior da gruta, todos os visitantes recebem equipamentos básicos como touca higiênica e capacete de uso obrigatório (Figura 2).

Porém outros detalhes também deveriam ser levados em consideração como o tipo de calçado utilizado pelos turistas. Devido à presença de animais peçonhentos/venenosos (ex: aranha marrom, serpentes). Foi observado algumas pessoas com sandálias e chinelos (Figura 3).

Um impacto significativo foi identificado no ano de 2003 em função da iluminação utilizada. As lâmpadas incandescentes que, devido ao forte calor que elas produzem juntamente com a umidade característica de ambiente cárstico, criavam 
musgos nos espeleotemas, modificando assim sua formação e coloração. Hoje toda a iluminação da gruta da Lapinha é feita com luzes de tecnologia LED (lâmpadas de Diodo que consomem menos energia e esquentam menos que as lâmpadas incandescentes), que diminuem significativamente este impacto (Figura 4).

Figuras 2 e 3: Grupo de turistas com equipamentos básicos e turista de sandália no interior da gruta, respectivamente.

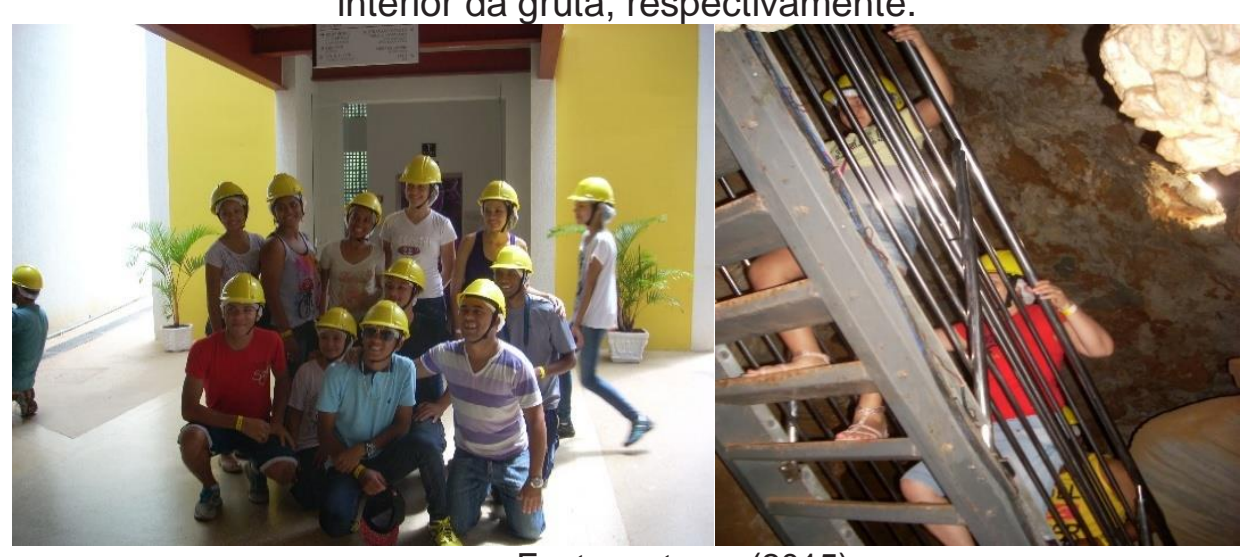

Fonte: autores (2015).

Figuras 4 e 5 (respectivamente): lluminação de LED e portão de segurança.

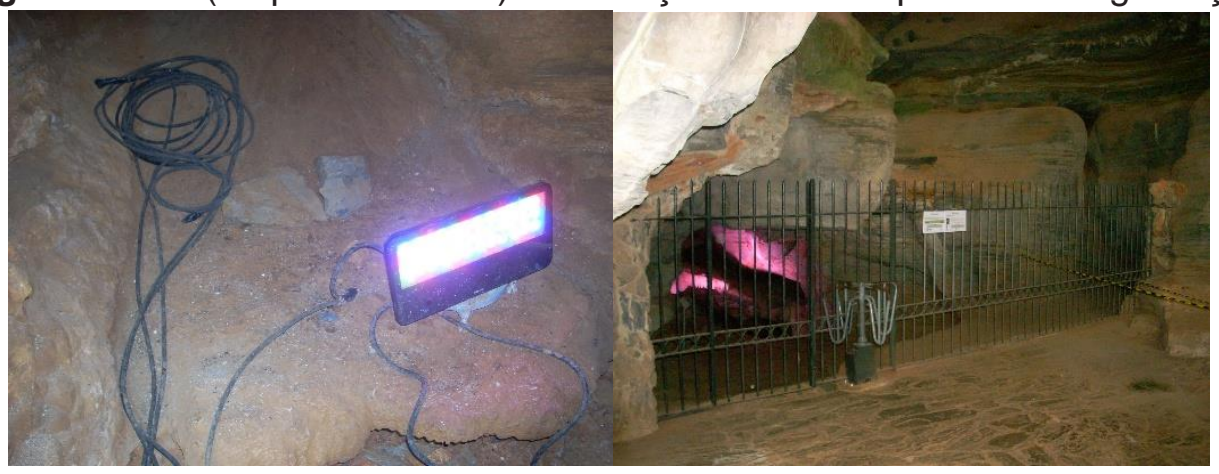

Fonte: autores (2015).

Para a iluminação da gruta, muitos fios e cabos são utilizados de maneira incorreta expondo a segurança dos visitantes com cabos desprotegidos e em locais de fácil acesso, aumentando assim o risco de algum acidente, além do impacto visual causado.

Outras interferências que impactam o ambiente natural não só visualmente, mas também fisicamente podem ser notadas. Logo na entrada existe um portão com roleta (Figura 5) para inibir a entrada de vândalos e também para um controle no acesso de visitantes.

Essas ações antrópicas interferem na constituição física do ambiente, mas tornam-se necessárias para preservação do patrimônio natural. Na Figura 6 pode-se 
Avaliação de impactos socioambientais na Gruta da Lapinha, Lagoa Santa/MG e seu entorno pela...

visualizar o um espeleotema sendo "protegido" por um muro e a proteção de guano (fezes de morcego) que é feita também com pedras alocadas em seu entorno (Figura 7). O guano é de suma importância para a vida troglóbia e por isso sua preservação.

Figuras 6 e 7 respectivamente.: Espeleotema protegido por muro e guano preservado.

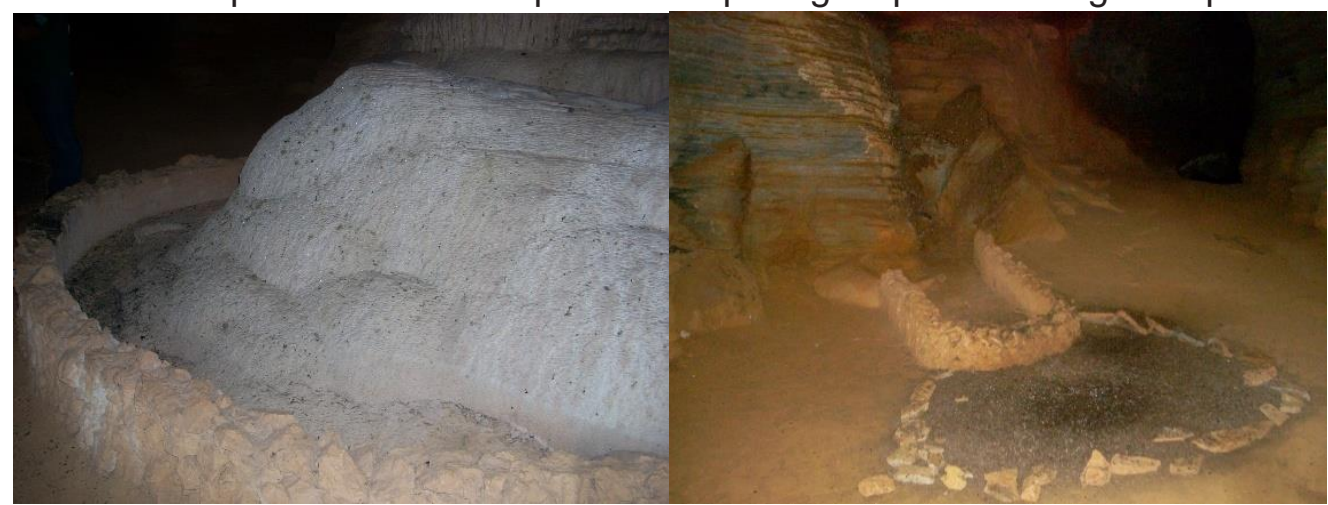

Fonte: autores (2015)

Ainda no interior da gruta, foi observada também a instalação e construção de escadas de ferro para facilitar a locomoção dos visitantes (Figura 8).

Figura 8: Instalação de ferro no interior da gruta da Lapinha

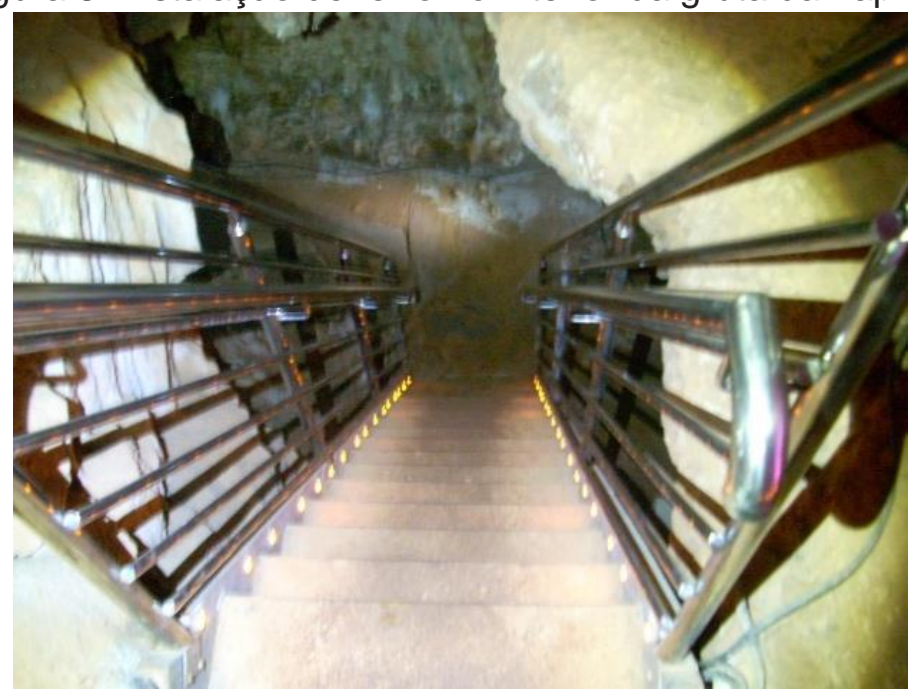

Fonte: autores (2015)

Durante o diálogo com os moradores, a dúvida comum observada é sobre 0 que seria um impacto ambiental e quais problemas eram gerados para a comunidade através disto. Surgiram dúvidas quando se perguntava se os órgãos ambientais ou a prefeitura colocavam regras para o uso do terreno; o que foi mais bem compreendido quando se questionava se eles podiam fazer o que queriam em seu entorno ou, se tinham algum limite ou regra. 
O Zoneamento Ambiental da APA Carste de Lagoa Santa foi realizado através da parceria entre o Instituto Brasileiro do Meio Ambiente e dos Recursos Naturais IBAMA e a Companhia de Pesquisa de Recursos Minerais - CPRM - e procurou construir uma visão de futuro para a APA, tendo como objetivo principal promover um processo de desenvolvimento sustentável, viabilizado a conjugação das limitações, potencialidades e fragilidades do ecossistema cárstico com as necessidades econômicas e sociais dos municípios envolvidos (SOUZA, 1997, p.10).

Segundo Mendonça (1998), cerca de 40\% da população total e urbana de Lagoa Santa se encontra dentro dos limites legais da APA. O município contribui com $21,49 \%$ da área total da APA, o que corresponde a um comprometimento de aproximadamente $33,32 \%$ da sua área municipal.

Em visitas a campo, em regiões abrangidas pela APA em Lagoa Santa, foram observados problemas relacionados à expansão urbana como: presença de loteamentos irregulares, com esgoto a céu aberto e ruas de terra perpendiculares às curvas de nível do terreno, favorecendo a ocorrência de processos erosivos e a poluição dos cursos dá água; expansão urbana sobre trechos de encostas de declive acentuada, com desmatamento de áreas próximas a nascentes, implicando em riscos à perenidade dos cursos d'água, erosão acelerada e assoreamento de rios; grandes áreas de pastagem não utilizadas, reservadas para especulação imobiliária; e a multiplicação de chácaras ou "casas de fim de semana".

De acordo com a lei $n^{\circ}$ 9.985, de 18 de julho de 200, art. 15; são objetivos de uma APA "proteger a diversidade biológica disciplinar o processo de ocupação e assegurar a sustentabilidade do uso dos recursos naturais". Partindo dessa premissa, pressupõe-se que a população local, que faz uso desses recursos naturais, deva ter envolvimento com a UC, como parte de sua avaliação de sua efetividade socioambiental.

Durante os trabalhos realizados em campo, foram levantados os seguintes temas: a situação sanitária na região, incluindo abastecimento de água, sistema de esgoto sanitário e coleta de lixo; a percepção de problemas ambientais na região; a relação entre os entrevistados, atrativos naturais e atividades de lazer na região; a relação e o conhecimento da população sobre a APA Carste de Lagoa Santa.

Segundo Mendonça (1998), o abastecimento de água dos municípios da APA é de origem subterrânea, obtida para distribuição a partir de poços tubulares profundos. Hoje, o abastecimento de água é realizado de forma coletiva o proporciona uma maior proteção ao manancial que abastece a população gerando um maior controle sobre a quantidade de água consumida. No entanto, o aumento populacional em regiões 
Avaliação de impactos socioambientais na Gruta da Lapinha, Lagoa Santa/MG e seu entorno pela...

cársticas gera duas grandes preocupações relacionadas ao abastecimento de água: determinados usos do solo podem contaminar a água subterrânea, comprometendo sua qualidade e colocando em risco a saúde da população, principalmente daquela que ainda é abastecida por poços rasos; o bombeamento excessivo de água pode induzir a formação de dolinas, gerando o risco de colapsos inesperados do solo.

Em geral, os maiores problemas na APA Carste de Lagoa Santa estão relacionados com expansão urbana desordenada, desmatamento irregular, agricultura e pecuária, queimadas, mineração de calcário com emissão de material particulado fino e de abalos provocados pelas detonações das frentes de lavras que, segundo os moradores, provocam tremores e fissuras nas casas.

A criação da APA Carste de Lagoa Santa tem por objetivo "proteger e preservar as cavernas e demais formações cársticas, sítios arqueo-paleontológicos", entre outros (Art. $2^{\circ}$ do Decreto $n^{\circ}$ 98.881, de 25/01/1990). Todos os moradores locais abordados conhecem alguma gruta ou sítio arqueológico na região. Por outro lado, este alto índice de relacionamento da população com o patrimônio espeleológico denota o despreparo dos municípios da região para lidar com o turismo esporádico e descontrolado. Essa atividade tem gerado historicamente a degradação do patrimônio, através de pichações, fogueiras, lixo, pisoteio de sedimento arqueológico, quebra de espeleotemas, roubo de peças arqueológicas, e uso indevido para manifestações religiosas (Figura 9), que retrata este uso na gruta da Macumba nos limites da APA.

São raras as cavernas inseridas na APA que não apresentam algum dos problemas descritos. A maior parte das grutas localizadas na APA tem o seu desenvolvimento predominantemente horizontal, sendo de fácil acesso ao visitante que as deixa mais vulneráveis. Apenas a gruta da Lapinha conta com infraestrutura para receber o turismo de massa.

Figura 9: restos de animal sacrificado para fins religiosos na gruta da Macumba.

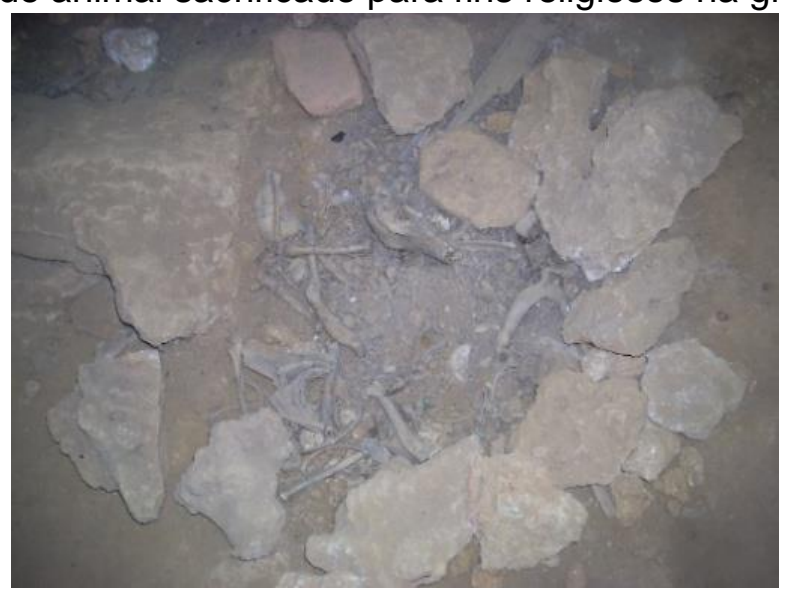

Fonte: autores (2015). 
Os moradores locais realizaram inúmeras reclamações sobre a falta de lugares e de atividades de lazer. O potencial de entretenimento e lazer na região é pouco explorado e, por outro lado a falta de lazer nos locais de residência pode estar contribuindo para a degradação de grutas e sítios arqueológicos nas proximidades, que não possuem planos de manejo e medidas de proteção.

\section{CONSIDERAÇÕES FINAIS E RECOMENDAÇÕES}

No decorrer deste trabalho, percebeu-se que o Parque do Sumidouro onde se localiza a gruta da Lapinha, não soube cativar a comunidade local no desenrolar do processo de implantação, pois cercou o local e gerou hostilidade da comunidade local. Apesar do Parque contar com funcionários que moram no distrito da Lapinha e região, não existe uma interação mais aproximada com a comunidade local. Os moradores, muitos de baixa renda, não possuem acesso gratuito ao Parque, o que causa desconforto e indignação.

É necessário um investimento sério em educação ambiental de modo que a comunidade seja integrada aos projetos vinculados ao Parque visando fomentar a economia local.

Uma proposta simples e que faria diferença seria a disponibilização de transporte em fins de semana, por exemplo, para que a comunidade local possa visitar c conhecer melhor o seu patrimônio.

A seguir são apresentadas algumas recomendações de ações que, se implementadas, poderão contribuir para o cumprimento dos objetivos do Parque Estadual do Sumidouro e da APA Carste de Lagoa Santa. Estas ações dependem de um olhar mais integrado e realista, que deve ser assumido tanto pelos órgãos públicos, quanto por todas as esferas da sociedade, direta ou indiretamente envolvidas. O IBAMA deve atuar de forma equilibrada em todos os municípios abrangidos pela APA ao invés de concentrar seus esforços no município de Lagoa Santa o que tem sido feito nos dias de hoje.

- É interessante que o Parque realize cursos e treinamentos para fiscalização e conhecimento da comunidade local em relação à Unidade de Conservação e aumente a fiscalização nas grutas que não possuem estrutura turística e estão abertas à visitação; 
Avaliação de impactos socioambientais na Gruta da Lapinha, Lagoa Santa/MG e seu entorno pela...

- Informar a comunidade local sobre a importância de se manter a integridade da Unidade de Conservação para que esta se mantenha preservada e diminua os impactos causados pela ação antrópica;

- Promover orientações sobre os valores patrimoniais específicos para os moradores do entorno e nas escolas além de participar de ações na comunidade promovendo campanhas sobre saneamento básico e tratamento de esgotos sanitários e de valorização dos córregos e das nascentes contribuintes na área do Parque e seu entorno;

- Promover maior possibilidade de fluxo genético interligando fragmentos florestais vizinhos, dentro do Parque, através da formação de corredores ecológicos;

- Elaborar o plano de manejo e aprimorar o monitoramento do estado de conservação da gruta da Lapinha;

- Incentivar as manifestações culturais e folclóricas tradicionais, além de permitir e monitorar as manifestações religiosas na gruta da Macumba;

- Incentivar a realização de expedições de caráter técnico, visando o levantamento de subsídios para o planejamento e gestão da visitação no Parque;

- Estabelecer parcerias formais com associações de escalada e espeleologia;

- Promover campanhas de recolhimento de lixo na área do Parque;

- Produzir material educativo sobre a região e sua ecologia, bem como de seus aspectos históricos, arqueológicos e culturais, direcionado às escolas com a utilização de linguagem adequada;

- Promover oficinas sobre temas úteis para a solução de problemas ambientais e de valorização das relações ente a sociedade e natureza;

Todas as propostas citadas, integram o Plano de Manejo Espeleológico com o intuito de que a gruta da Lapinha possa realmente cumprir seu papel: o de educar as pessoas da importância da preservação do patrimônio Espeleológico.

Assim, para a preservação efetiva da região é necessário pensar no ambiente cárstico enquanto um sistema, cujos componentes são estão interligados e isso inclui também um dos principais agentes de transformação do meio - a comunidade local.

\section{REFERÊNCIAS}

BERBERT-BORN, M. Carste de Lagoa Santa, MG: berço da paleontologia e da espeleologia brasileira. In: Schobbenhaus, C.; Campos, D.A.; Queiroz. E.T.; Winge, M.; Berbert-Born, M. (eds.), Sítios Geológicos e Paleontológicos do Brasil (SIGEP-5), CPRM, 415-430, 2008.

CONSELHO NACIONAL DO MEIO AMBIENTE. Resolução CONAMA n 347 de 10 de setembro de 2004. In: Diário Oficial da União, Brasília, 176: 1. 54p. 13 set. 2004. 
DIEGUES, A. C. O Mito Moderno da Natureza Intocada. Editora Hucitec, São Paulo, 2004.

KOHLER, H. C. Geomorfologia Cárstica da Região de Lagoa Santa, MG. São

Paulo: FFLCH-USP, (Tese de doutorado), 1989.

MENDONÇA, L. Socioeconômica. Belo Horizonte: IBAMA/Fund.

BIODIVERSITAS/CPRM, 66p. (Série APA Carste de Lagoa Santa - MG).1998.

NEVES, W. A.; PILÓ, L. B.; ATUI, J.P.V. Holocene dryness and human occupation in Brazil during the Archaic Gap. Quaternary Research, Washington, 64: 298-307, 2005.

PROUS, A., FOGAÇA, E., RIBEIRO, L. - Patrimônio arqueológico. In: APA Carste de Lagoa Santa - Patrimônio Espeleológico, Histórico e Cultural. Belo Horizonte, CPRM/ IBAMA. 22 p., anexos e mapas. (Série APA Carste de Lagoa Santa, volume III), 1998.

SANCHÉZ, L. E. Avaliação de Impacto Ambiental: conceitos/métodos - São Paulo: oficina de textos, 2008.

SOUZA, H. (org.). Zoneamento ambiental da APA Carste de Lagoa Santa. Belo Horizonte, CPRM/IBAMA. (Série APA Carste de Lagoa Santa). 1997

\footnotetext{
${ }^{1}$ Fernanda Vieira Xavier. Professora Dept ${ }^{\circ}$ de Geografia Universidade do Estado de Mato Grosso - UNEMAT/Cáceres, MT. Geógrafa, Doutora em Geociências e Meio Ambiente UNESP/Rio Claro, SP. Rua Travessa do Cururu, n 66, casa 6, Cavalhada, Cáceres, MT CEP: 78200-000. ferx.unesp@gmail.com

${ }^{2}$ Rafael Deslandes Ribas. Pós - graduando em Avaliação de Impactos Ambientas e Recuperação de Áreas Degradadas pelo Centro Educacional - UNIBH; Coordenador de seleção de áreas para recuperação ambiental - Instituto Espinhaço, MG. Rua José Sena, 483A. Conceição do Mato Dentro. CEP: 35860-000.rdribas@hotmail.com

${ }^{3}$ Adalto Moreira Braz. Geógrafo. Doutorando em Geografia UFG-REJ/Jataí, GO. UFG, rua Riachuelo, CP03. CEP: 75804-020. Jataí, GO. adaltobraz.geografia@gmail.com
} 